\title{
Optimization of Flexural Strength of Recycled Polyethylene- terephthalate (PET) Eco-Composite using Response Surface Methodology
}

\author{
Abayomi Abayomi Akinwande ${ }^{1}$, Adeolu Adesoji Adediran ${ }^{2 *}$, Oluwatosin Abiodun Balogun ${ }^{1}$, Bayode Julius Olorunfemi ${ }^{3}$, \\ and M. Saravana Kumar $^{4}$ \\ ${ }^{1}$ Department of Metallurgical and Materials Engineering, Federal University of Technology, Akure, Ondo State, Nigeria. \\ ${ }^{2}$ Department of Mechanical Engineering, Landmark University, Omu-Aran, Kwara State, Nigeria. \\ ${ }^{3}$ Department of Mechanical Engineering, Federal University Oye-Ekiti, Ekiti State, Nigeria. \\ ${ }^{4}$ Department of Mechanical Engineering, Mount Zion College of Engineering and Technology, Tamil Nadu, India
}

\begin{abstract}
Recycling and reuse of plastic waste by blending with virgin polymer has been affirmed to be the best way of managing the waste. Equally, agro-waste are best recycled than being burnt off. In the development of stronger and cheaper ecoefficient recycled PET composite for food packaging, this study focused on reinforcement of the blend of $20 \mathrm{wt}$. \% recycled PET (rPET) and $80 \mathrm{wt}$ \% virgin PET (vPET) with snail shell particulate and kenaf fiber via compression moulding process. The process parameters are fiber dosage, particulate dosage, moulding pressure and temperature. Box-Behnken design was engaged in the design of experiment and the samples were produced according to the experimental runs. Result of analysis of variance pinpointed the process factors as significant contributors to the flexural strength response. The model developed was validated to be significant and statistically fit. Interactions between the process variables as revealed by the response surface plots indicated the response was dependent on the interactive pattern between the variables. Response surface optimization showed an optimum flexural strength of $57.16 \mathrm{MPa}$ was attainable at process parameters of $27.27 \mathrm{wt} . \%, 4.18 \mathrm{wt}$. $\%, 3.95 \mathrm{MPa}$, and 160 ${ }^{\circ} \mathrm{C}$ for fiber proportion, particulate proportion, moulding pressure and temperature respectively yielding 34.2 $\%$ improvement over the reference $80 / 20$-vPET/rPET matrix. Model validation experiment undergone with the combined parameters and deviation of +0.036 was noted. Since the deviation is insignificant, the model is concluded to be statistically fit for predicting the flexural strength of the developed eco-composite.
\end{abstract}

\section{Introduction}

Studies on waste management has been one area of concern for researchers based on the consequence of the nuisance the waste constitute to the environment. Different strategies are involved in managing refuse and unwanted materials from their incipience to final disposal. These activities are carried out not only to eradicate the wastes, but also to protect the environment, for the sake of healthy living $[1,2]$. Sources of wastes include agricultural, industrial, domestic, and environmental. Unwanted products are categorized based on their biodegradability. Biodegradable wastes such as food and agro by products, vegetables, fruit peels, dead plant and animal decompose themselves over a period of time, while non-biodegradable like plastic bottles, broken glasses, metal can, electronics and automobile parts do not decompose easily $[3,4]$.

Disposed plastics are one of the widely known waste littering our environment and water bodies effect of which contribute negatively to the degradation of the environment. Varying approaches have been harnessed onto disposing the waste one of which is incineration (burning at high temperature). Incineration process is effective in reducing the nudniks. Nevertheless, the approach generates toxic gas such as oxides of nitrogen, sulphur and carbon, which can be harmful to human health as well as contribute to the problem of climate change $[5,6]$. Another process entails reprocessing of waste plastic into useful products; known as plastic recycling process. This approach tagged in some climes as "waste to wealth" has been encouraged and is the main interest in several modern-day research. Polyethylene terephthalate (PET) amongst other thermoplastics is often used in food packaging as bottles for carbonated and alcoholic drinks, crates for transporting eggs, food trays, beverages packaging due to its versatility, durability and light weight.

During the ages of industrial revolution, virgin PET amidst other forms of thermoplastics was used for food packaging products. Notwithstanding, with increasing number of plastic wastes in the environment several decades after, recycled PET (rPET) was encouraged to be blended with virgin PET (VPET) in different ratios. Purpose of the concept was for the recycling and reusing of the effluvia in the production of end use plastic products $[7,8]$. The initiative has achieved a lot and has become a norm nowadays in industrial process. Another 
merit associated with the concept is the reduced cost of the end use plastic products.

Series of investigations have been involved in the blend of $\mathrm{rPET} / \mathrm{vPET}$ in different proportions $[9,10]$. Results had shown that with increasing rPET proportion, the properties are reduced owing to degradation of the recycled plastic during the process [11]. Based on records of achievement of reinforcing additive in property enhancement of base-polymer [12, 13], their incorporation into $\mathrm{rPET} / \mathrm{vPET}$ matrix should be studied for property enhancement of the blend.

According to [14], polymeric food packaging materials like egg crate fail in service mostly on account of flexural, compressive and impact failure, instigating the need for stronger material. Some of the reinforcing additives are agro waste in form of particulate or fibers or both as observed in [15 - 19]. The choice of recycling and reusing agro waste in meaningful applications provides eco-friendly materials imputable to the biodegradability of the agro-by-products. This study considered blending of VPET with rPET in the ratio of $80 / 20$ [20] for the reference mix and considering reinforcement with agro-by product of snail shell particles and kenaf fiber. The reinforcements were introduced as partial replacement of the virgin PET so as to appraise effect of these reinforcement on the flexural behaviour of developed composite.

Compression moulding technique is a common procedure in the processing of polymer composite at varying proportion of reinforcement, howbeit, there are limited study on the modelling and optimization of the processing/operation factors. Present work considered the modelling and optimization of the flexural strength and process parameters in the development of snail shell/kenaf fiber-recycled PET ecoefficient-composite for food packaging using response surface method. The method has gained ground in optimization procedures as implemented in different studies as a useful tool in predicting responses [21 - 24]. Hence, RSM is inspired in this study for optimization of the process parameters and flexural strength response. Experimental factors varied in the compression moulding process are fiber dosage, particulate dosage, moulding pressure and moulding temperature.

\section{Materials Preparation}

Materials utilized in the course of the investigation are kenaf fiber, snail shell, virgin PET and recycled PET pellets. The kenaf fiber was cleaned in water maintained at $35{ }^{\circ} \mathrm{C}$ to removed impurities and later dried in the open for 2 days. Sequel to that, the fibers were cut into length of $25 \mathrm{~mm}$ before being treated with $0.8 \%$ stearic acid based on the outcome of [25]. The treated fibers (Fig. 1a), were then washed in distilled water and dried in the oven maintained at $50{ }^{\circ} \mathrm{C}$ for a period of $8 \mathrm{hrs}$. Procured snail shells were washed in water maintained at $35^{\circ} \mathrm{C}$ so as to remove attached impurities. Next was the drying of the shells in open air for 3 days before being crushed, pulverized and sieved via laboratory electric sieve shaker. Portion of the snail shell sieved to -25 gm (Fig. 1b), was collected, and dried in the oven at
$40{ }^{\circ} \mathrm{C}$ for a period of $2 \mathrm{hrs}$. Adoption of $25 \mu \mathrm{m}$ size in the investigation is linked to observations realized in [26].

Table 1. Levels of factors in the design of experiment

\begin{tabular}{|l|l|l|l|}
\hline Factors & $\begin{array}{l}\text { Low level } \\
(-1)\end{array}$ & $\begin{array}{l}\text { Medium } \\
\text { level (0) }\end{array}$ & $\begin{array}{l}\text { High level } \\
(+1)\end{array}$ \\
\hline $\begin{array}{l}\text { Fiber } \\
\text { dosage } \\
(\text { A) }\end{array}$ & $5 \mathrm{wt} . \%$ & $10 \mathrm{wt} \%$ & $15 \mathrm{wt} . \%$ \\
\hline $\begin{array}{l}\text { Particulate } \\
\text { dosage } \\
\text { (B) }\end{array}$ & $2 \mathrm{wt.} \%$ & $4 \mathrm{wt} \%$ & $6 \mathrm{wt} \%$ \\
\hline $\begin{array}{l}\text { Moulding } \\
\text { pressure (C) }\end{array}$ & $1 \mathrm{MPa}$ & $2 \mathrm{MPa}$ & $3 \mathrm{MPa}$ \\
\hline $\begin{array}{l}\text { Moulding } \\
\text { temperature } \\
(\mathrm{D})\end{array}$ & $160{ }^{\circ} \mathrm{C}$ & $180{ }^{\circ} \mathrm{C}$ & $200{ }^{\circ} \mathrm{C}$ \\
\hline
\end{tabular}

\subsection{Experimental Design and Procedure}

Box-Behnken approach of the response surface method was employed in the design of experiment. Experimental factors are fiber dosage (A), particulate dosage (B), moulding pressure (C) and moulding temperature (D) and are varied as illustrated in Table 1 for the design. The three level -four factor design was carried out using Minitab 19 involving 21 experimental runs (Table 2) for the flexural strength response. Composites were developed using compression moulding machine (NG-PUT-P11) according to the runs stipulated in Table 2. Initial reference material was produced by the blend of $80 \%$ virgin PET with $20 \%$ recycled PET and designated $80-v P E T / 20-r P E T$. The fiber and agro fillers were used as partial replacement of the virgin PET in the composites. Samples were left to cure for $24 \mathrm{hrs}$. Before careful ejection from the moulds. Flexural test samples were prepared using a mould of dimension $150 \times 50 \times 3(\mathrm{~mm} 3)$ according to [27]. Threepoint bending test was carried out on the samples with the use of a universal testing machine (Instron 3369 series) in accordance with ASTM D 790-17 [28]. In the course of the test, span length of $100 \mathrm{~mm}$ was employed while load of $100 \mathrm{~N}$ was applied at crosshead speed of $10 \mathrm{~mm} / \mathrm{min}$.

Table 2. Coded levels and factors

\begin{tabular}{ccccc|ccccc}
\hline \multicolumn{7}{c|}{ Coded levels } & \multicolumn{7}{c|}{ Factors } & Response \\
\hline Runs & A & B & C & D & A & B & C & D & $\begin{array}{c}\text { Flexural } \\
\text { strength } \\
(\mathrm{MPa})\end{array}$ \\
\hline & & & & & & & & & \\
\hline 1 & 0 & 0 & 1 & -1 & 10 & 4 & 1 & 200 & 30.8 \\
2 & 1 & -1 & 0 & 0 & 10 & 2 & 3 & 180 & 42.6 \\
3 & - & 0 & 1 & 0 & 10 & 6 & 2 & 160 & \\
& 1 & & & & & & & & 35.8 \\
4 & - & 0 & -1 & 0 & 10 & 2 & 2 & 200 & \\
& 1 & & & & & & & & 37.1 \\
5 & 0 & 0 & 0 & 0 & 10 & 4 & 1 & 160 & 49.2 \\
6 & 0 & 1 & 0 & 1 & 10 & 4 & 2 & 180 & 41.8 \\
7 & 0 & 1 & -1 & 0 & 5 & 4 & 2 & 200 & 33.4 \\
8 & - & -1 & 0 & 0 & 5 & 6 & 2 & 180 & \\
& 1 & & & & & & & & 35.8 \\
9 & 0 & -1 & -1 & 0 & 5 & 4 & 1 & 180 & 37.4 \\
10 & 0 & -1 & 1 & 0 & 5 & 2 & 2 & 180 & 40.4 \\
11 & - & 0 & 0 & -1 & 5 & 4 & 3 & 180 & \\
& 1 & & & & & & & & 51.8 \\
12 & 0 & 0 & 0 & 0 & 15 & 4 & 2 & 200 & 44.5
\end{tabular}




\begin{tabular}{ccccc|ccccc}
13 & - & 0 & 0 & 1 & 10 & 4 & 2 & 180 & \\
& 1 & & & & & & & & 47.5 \\
14 & 0 & -1 & 0 & -1 & 10 & 2 & 1 & 180 & 58.4 \\
15 & 1 & 0 & -1 & 0 & 15 & 2 & 2 & 180 & 50.5 \\
16 & 0 & 0 & 0 & 0 & 15 & 6 & 2 & 180 & 43.6 \\
17 & 1 & 0 & 0 & 1 & 10 & 4 & 3 & 160 & 54.6 \\
18 & 0 & 1 & 0 & -1 & 15 & 4 & 2 & 160 & 46.8 \\
19 & 0 & 0 & -1 & 1 & 10 & 4 & 3 & 200 & 35.5 \\
20 & 1 & 0 & 0 & -1 & 10 & 2 & 2 & 160 & 46.5 \\
21 & 0 & 1 & 1 & 0 & 10 & 6 & 3 & 180 & 39.2 \\
22 & 1 & 1 & 0 & 0 & 10 & 4 & 2 & 180 & 42.8 \\
23 & 0 & 0 & 1 & 1 & 15 & 4 & 1 & 180 & 54.1 \\
24 & - & 1 & 0 & 0 & 10 & 6 & 1 & 180 & \\
& 1 & & & & & & & & 45.2 \\
25 & 0 & 0 & -1 & -1 & 15 & 4 & 3 & 180 & 38.4 \\
26 & 1 & 0 & 1 & 0 & 10 & 6 & 2 & 200 & 49.2 \\
27 & 0 & -1 & 0 & 1 & 5 & 4 & 2 & 160 & 41.6 \\
\hline A
\end{tabular}

$\mathrm{A}$ is fiber dosage (wt. \%), $\mathrm{B}$ is particulate dosage (wt. $\%), \mathrm{C}$ is moulding pressure (MPa) and $\mathrm{D}$ is moulding temperature $\left({ }^{\circ} \mathrm{C}\right)$.
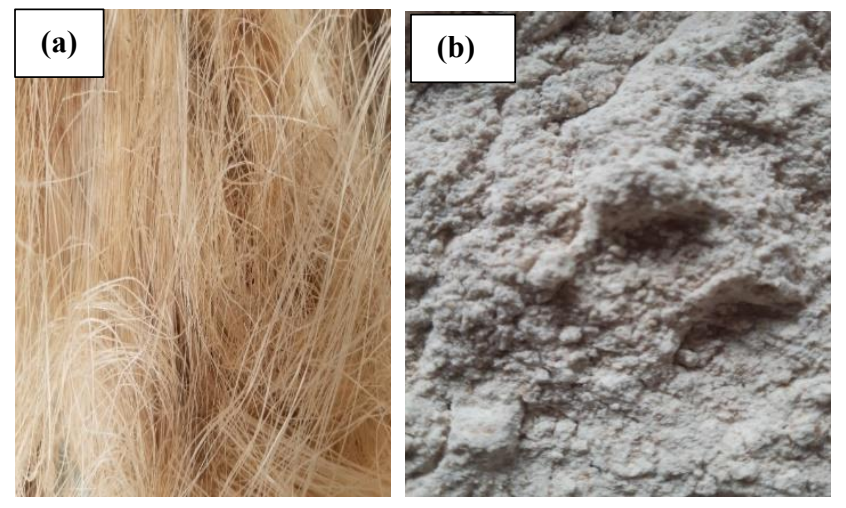

Fig. 1. Image of input materials (a) kenaf fiber (b) Particulate snail shell.
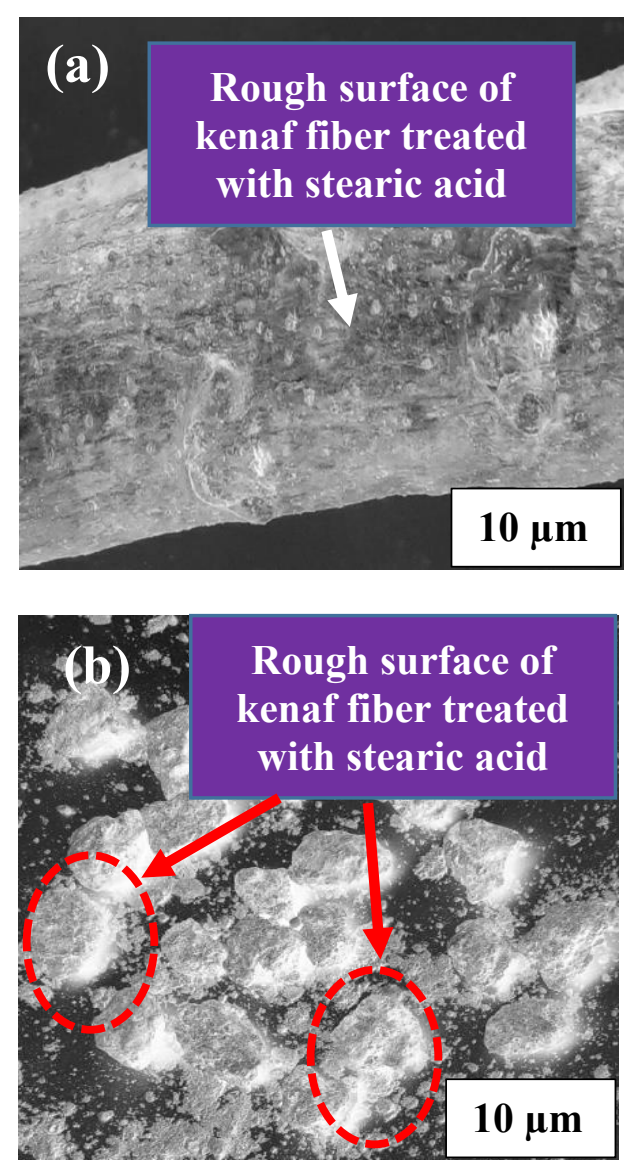

Fig. 2. Morphological images of input materials (a) kenaf fiber (b) Particulate snail shell

Table 3. Chemical constituents of treated kenaf fiber used in the study

\begin{tabular}{|l|l|}
\hline \multicolumn{2}{|c|}{ Used in the study } \\
\hline Cellulose & Amount \\
\hline Hemicellulose & 52.3 \\
\hline Lignin & 22.4 \\
\hline Moisture & 7.9 \\
\hline Ash & 6.4 \\
\hline Others & 3.4 \\
\hline
\end{tabular}

Table 4. Chemical composition of particulate snail shell employed in present investigation

\begin{tabular}{|l|l|}
\hline Compound & Amount \\
\hline $\mathrm{CaO}$ & 59.8 \\
\hline $\mathrm{SiO}_{2}$ & 0.89 \\
\hline $\mathrm{Al}_{2} \mathrm{O}_{3}$ & 0.16 \\
\hline $\mathrm{Fe}_{2} \mathrm{O}_{3}$ & 0.78 \\
\hline $\mathrm{MnO}$ & 0.06 \\
\hline $\mathrm{MgO}$ & 0.96 \\
\hline $\mathrm{Na}_{2} \mathrm{O}$ & 1.05 \\
\hline Others & 4.81 \\
\hline LOI & 31.33 \\
\hline
\end{tabular}

Surface treatment of kenaf fiber by $0.8 \%$ stearic acid ensued revelation of the rough surface of the fiber associated with the removal of wax and impurities and surface restructuring. The surface is therefore enhanced to attach to matrix resulting in improved property. Table 3 present the chemical content of the treated fiber with cellulose having the largest share. Chemical composition of the snail shell is highlighted in Table 4 from which it is deduced that $\mathrm{CaO}$ has highest proportion in the material contributing to strength of the developed eco-composites when the particulate was infused into the 80-vPET/20-rPET matrix. Fig. 2b shows the morphological features of the snail shape particulate; mostly spherical. The shape enhanced the filling of pores present in matrix thereby decreasing inter-particle distance. The consequence is improvement of strength of the composite.

\section{Results and Discussion}

\subsection{ANOVA and model representation}

The study was conducted to obtain effect of fiber dosage, particulate dosage, moulding pressure and temperature on the flexural strength response of the developed eco-composites with the view of optimizing the strength. Flexural strength of the eco-composite is dependent on composition, and operating conditions in which case response surface method was adopted to observe the relationship between the parameters as they affect the response. ANOVA presents $p$ values and percentage contributions of experimental parameters at $95 \%$ confidence level. The lower the $\mathrm{p}$ value from 0.05 , the more significant the coefficients and contribution to the response. From the table, the model is statistically significant at $95 \%$ confidence level since $\mathrm{p}<0.005$. 
Process factors A, B, C and D are significant model terms by virtue of the $p$ value being $<0.05$. The square interactions are statistically insignificant that is they are insignificant interaction terms of the model. The cross interactions between the parameters had significant effect on the response $(\mathrm{p}<0.05)$, so are the significant interaction terms of the model. Equally, the error observed is insignificant. Lack of fit refers to variation of data from the fitted model. In this case (Table 5), the lack of fit is insignificant since $p>0.05$, hence, there is a good response to the model. Coefficient of determination R2 is 0.971 showing a good agreement between the response data and the model, indicating $97.1 \%$ of the variability is represented by the model while residual variability is $2.9 \%$. The quadratic function of the model is represented in equation (1).

Table 3. Analysis of variance for flexural strength of the eco-

\begin{tabular}{|c|c|c|c|c|c|}
\hline Source & DF & Seq SS & \begin{tabular}{|c|} 
F- \\
Valu \\
e \\
\end{tabular} & \begin{tabular}{|c|} 
P- \\
Valu \\
e \\
\end{tabular} & Contribution \\
\hline Model & 14 & 4061.69 & $\begin{array}{c}536 . \\
22 \\
\end{array}$ & $\begin{array}{c}0.00 \\
0 \\
\end{array}$ & $97.10 \%$ \\
\hline Fiber & 1 & 2179.31 & $\begin{array}{c}228 . \\
39 \\
\end{array}$ & $\begin{array}{c}0.00 \\
0\end{array}$ & $17.62 \%$ \\
\hline Particles & 1 & 1030.83 & $\begin{array}{c}129 . \\
85\end{array}$ & \begin{tabular}{|c|}
0.00 \\
4
\end{tabular} & $9.14 \%$ \\
\hline Pressure & 1 & 2302.46 & $\begin{array}{c}322 . \\
76 \\
\end{array}$ & \begin{tabular}{|c|}
0.00 \\
0
\end{tabular} & $20.64 \%$ \\
\hline Temperature & 1 & 77.36 & $\begin{array}{c}204 . \\
51\end{array}$ & $\begin{array}{c}0.16 \\
0 \\
\end{array}$ & $11.72 \%$ \\
\hline Fiber*Fiber & 1 & 67.45 & $\begin{array}{c}25.8 \\
2 \\
\end{array}$ & \begin{tabular}{|c|}
0.16 \\
0 \\
\end{tabular} & $0.72 \%$ \\
\hline Particles*Particles & 1 & 65.46 & $\begin{array}{c}18.1 \\
1 \\
\end{array}$ & \begin{tabular}{|c|}
0.18 \\
0
\end{tabular} & $0.31 \%$ \\
\hline Pressure*Pressure & 1 & 129.64 & 1.52 & \begin{tabular}{|c|}
0.51 \\
5
\end{tabular} & $2.92 \%$ \\
\hline $\begin{array}{c}\text { Temperature*Temp } \\
\text { erature }\end{array}$ & 1 & 543.44 & $\begin{array}{c}89.4 \\
3 \\
\end{array}$ & \begin{tabular}{|c|}
0.95 \\
5 \\
\end{tabular} & $1.17 \%$ \\
\hline Fiber*Particles & 1 & 460.61 & $\begin{array}{c}86.0 \\
8 \\
\end{array}$ & \begin{tabular}{|c|}
0.01 \\
9 \\
\end{tabular} & $5.11 \%$ \\
\hline Fiber*Pressure & 1 & 611.07 & $\begin{array}{c}97.0 \\
1 \\
\end{array}$ & $\begin{array}{c}0.00 \\
7\end{array}$ & $7.00 \%$ \\
\hline Fiber*Temperature & 1 & 538.84 & $\begin{array}{c}71.1 \\
0 \\
\end{array}$ & \begin{tabular}{|c|}
0.02 \\
2 \\
\end{tabular} & $5.02 \%$ \\
\hline Particles*Pressure & 1 & 588.47 & $\begin{array}{c}92.6 \\
8 \\
\end{array}$ & \begin{tabular}{|c|}
0.00 \\
9 \\
\end{tabular} & $6.47 \%$ \\
\hline $\begin{array}{c}\text { Particles*Temperat } \\
\text { ure }\end{array}$ & 1 & 430.03 & $\begin{array}{c}70.0 \\
0 \\
\end{array}$ & \begin{tabular}{|c|}
0.01 \\
9 \\
\end{tabular} & $5.10 \%$ \\
\hline $\begin{array}{c}\text { Pressure*Temperatu } \\
\text { re }\end{array}$ & 1 & 522.72 & $\begin{array}{c}90.8 \\
4 \\
\end{array}$ & \begin{tabular}{|c|}
0.01 \\
2
\end{tabular} & $6.39 \%$ \\
\hline Residual & 9 & 94.67 & & & \\
\hline Lack of fit & 3 & 5.62 & 2.56 & \begin{tabular}{|c|}
0.95 \\
8 \\
\end{tabular} & $2.67 \%$ \\
\hline Error & 6 & 328.64 & & & $2.90 \%$ \\
\hline Total & 80 & 7590.33 & & & $100.00 \%$ \\
\hline $\mathrm{R}^{2}=0.971$ & \multicolumn{2}{|c|}{ Adj $R^{2}=0.923$} & \multicolumn{2}{|c|}{$\begin{array}{c}\text { Pred. } \mathrm{R}^{2}= \\
0.817\end{array}$} & $\begin{array}{c}\text { Adeq. Pre }= \\
16.78\end{array}$ \\
\hline
\end{tabular}

Contributions of process variables $\mathrm{A}, \mathrm{B}, \mathrm{C}$ and $\mathrm{D}$ are $17.62,9.14,20.64$ and 11.72 respectively. Hence, moulding pressure is the most important parameters, followed by fiber dosage, temperature and particle dosage in that order. A positive coefficient of the parameters in the model reflects a synergistic effect in that as the parameters increase from low to high, response increase. The negative coefficient is indicative of antagonistic influence that is change in the parameters from low to high has negative influence on the response. From the quadratic model expression (equation 1), factor $\mathrm{D}$ which is temperature and the combine interactions involving temperature has negative coefficient in the model, implication of which reflected negative effect on the response. Therefore, temperature has an antagonistic effect on the response.

$\mathrm{FS}=50.7+1.686 A+10.22 B+16.22 C-0.541 D-$ $0.0029 A^{2}-0.00127 B^{2}-0.00232 C^{2}-0.0011 D^{2}-$ $0.44 A * B-0.15 A * C-0.52 A * D+0.193 B * C-$ $0.0008 B * D-0.0199 C * D$

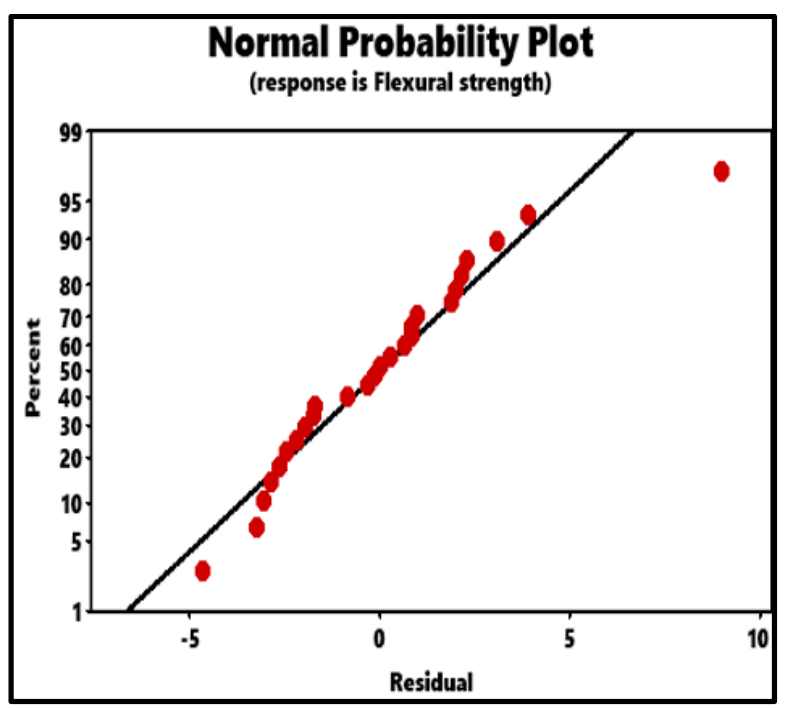

(a)

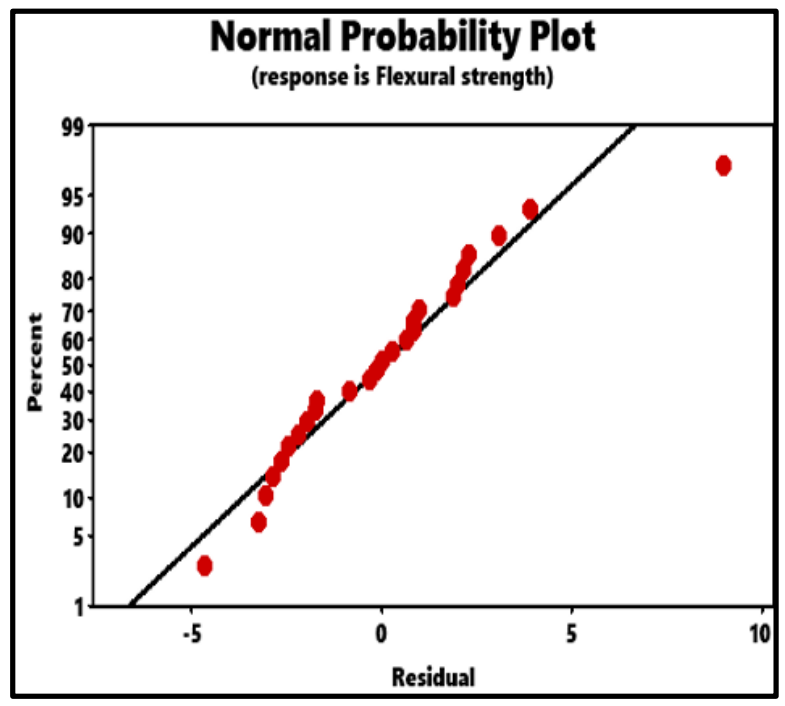

(b)

Fig 3. (a) Normal probability plot and (b) versus fit for flexural strength

Further test for the model is revealed in Fig. 3a for the probability plot. The points are located round the fit line with one outliner depicting a good response of the model. Fig. $3 \mathrm{~b}$ shows that the residual falls on a straight with few outliners, therefore, the errors are almost equally distributed. That means all experimental data points are almost uniformly distributed around the mean 
response therefore the model is adequate representation of the data [29]. As represented in Table ANOVA, the difference between adjusted $\mathrm{R}^{2}$ and predicted $\mathrm{R}^{2}$ is $<0.2$ and model adequacy precision is $>4$ depicting a fit and adequate model [30]. Adequate precision measures the signal to noise ratio $(\mathrm{S} / \mathrm{N})$ by evaluating ratio of the difference between maximum predicted response and minimum predicted response by the mean standard deviation for all predicted responses.

\subsection{Response surface plot}

Authors [31] defined response (3D) surface plots as exhibit of two variables interaction keeping the other parameters constant. Effect of the interaction between the factors on the flexural strength response is presented in Fig. 4. Fig. 4a exhibit the interaction between fiber dosage and particulate dosage while pressure and temperature were held at $2 \mathrm{MPa}$ and $180{ }^{\circ} \mathrm{C}$ respectively. As fiber and particulate increased, flexural strength was enhanced, however, beyond $10 \mathrm{wt}$. $\%$ and 4 wt. $\%$ respective dosage of fiber and particulate, the strength trended downwards.

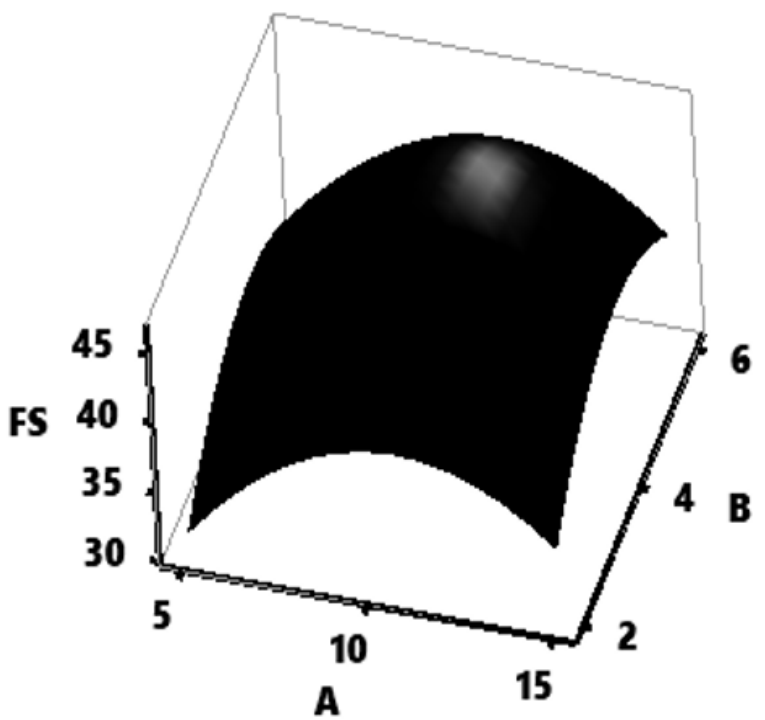

(a)

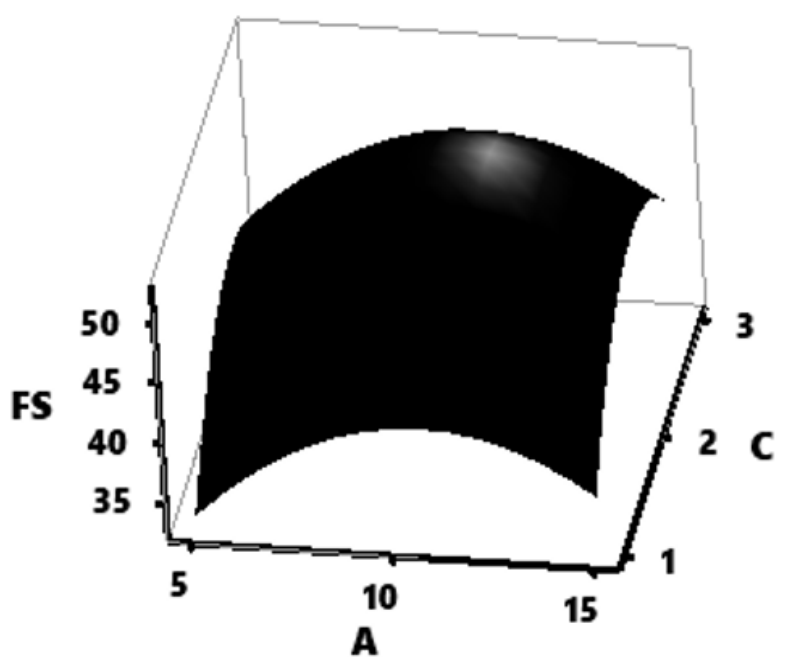

(b)

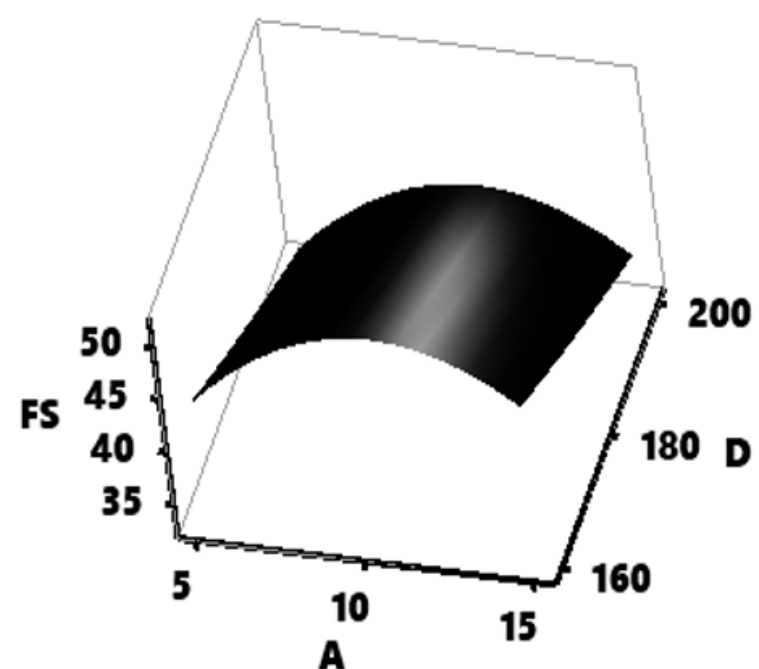

(c)

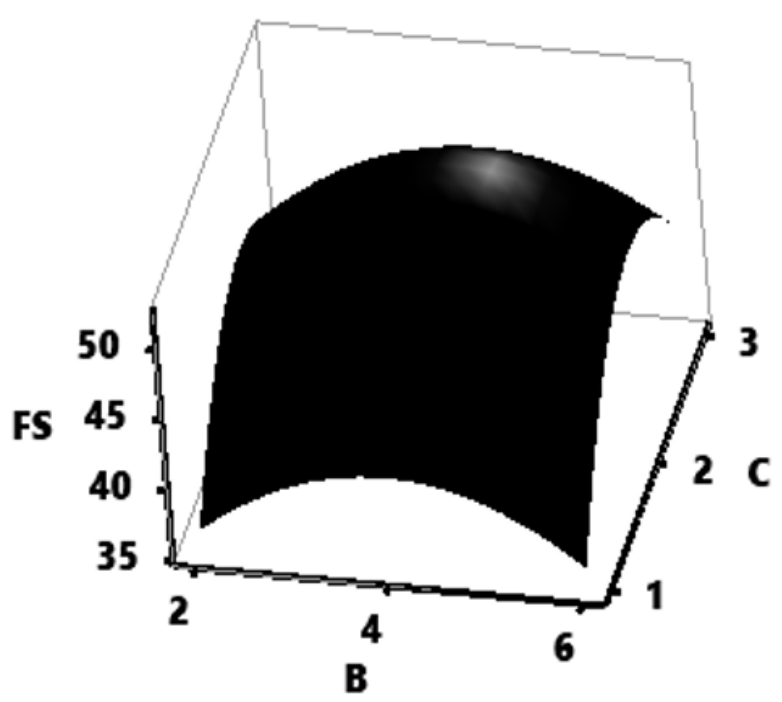

(d) 


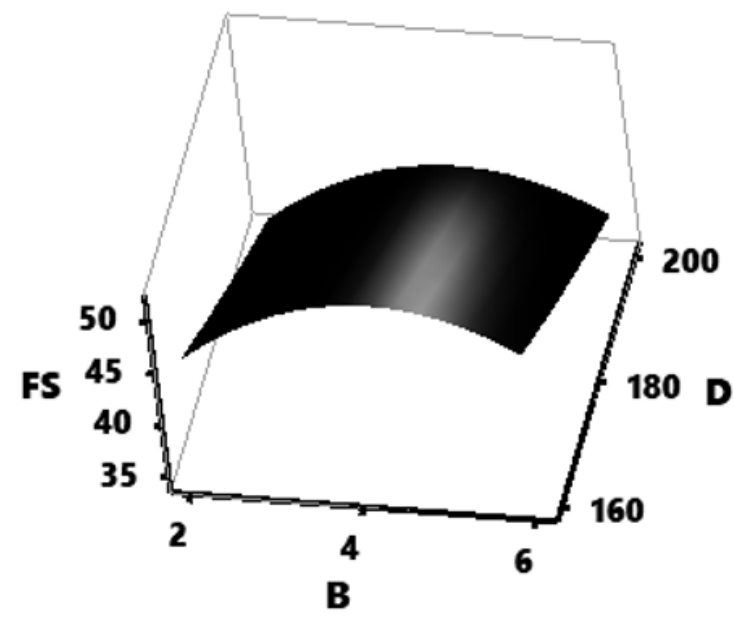

(e)

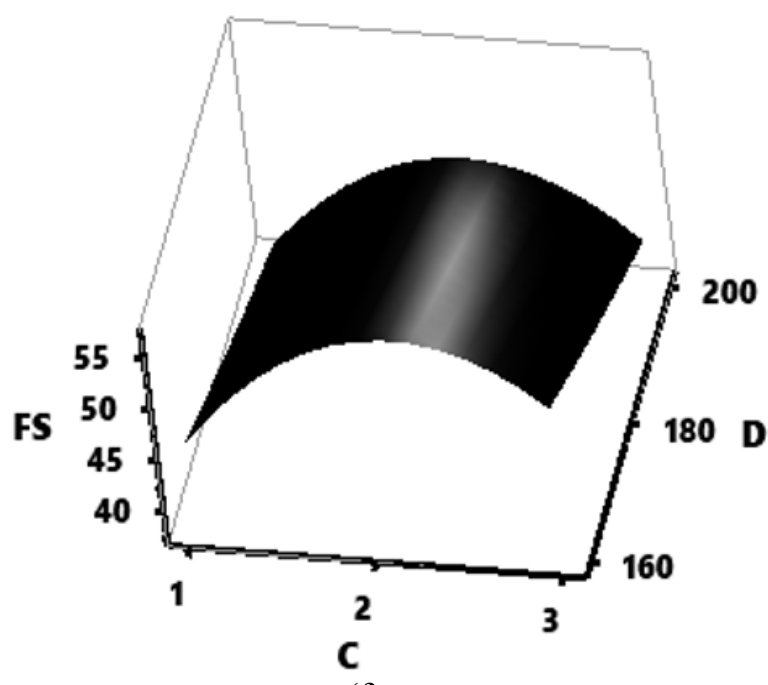

(f)

Fig 4. FS is flexural strength (MPa), A is fiber dosage (wt. $\%$ ), $\mathrm{B}$ is particulate dosage (wt. \%), $\mathrm{C}$ is moulding pressure (MPa) and D is moulding temperature $\left({ }^{\circ} \mathrm{C}\right)$.

Fig. 4 Interactions of moulding parameters on flexural strength of developed eco-composite as represented by response surface plot (a) fiber vs particulate (b) fiber vs pressure (c) fiber vs temperature (d) particulate vs pressure (e) particulate vs temperature (f) pressure vs temperature. Same goes with interaction between fiber dosage and pressure, holding particulate dosage and temperature at 4 wt. $\%$ and $180{ }^{\circ} \mathrm{C}$ serially in Fig $4 \mathrm{~b}$. Interaction between fiber content and pressure ensued strength enhancement, though, beyond $10 \mathrm{wt}$. \% fiber and $2 \mathrm{MPa}$ pressure, strength reduction sprouted. In Fig.4c, while holding particulate dosage and pressure at 4 wt. $\%$ and $2 \mathrm{MPa}$ respectively, FS improved with fiber dosage up to $10 \mathrm{wt}$. \% even as increased temperature led to reduction in strength. Therefore, there is an inverse interaction between fiber dosage and temperature. In Fig. 4d, interaction between particulate dosage and pressure at constant fiber dosage of 10 wt. $\%$ and temperature $180{ }^{\circ} \mathrm{C}$ is presented. Below 4 wt. $\%$ and 2 $\mathrm{MPa}$ for particulate dosage and pressure respectively, strength was enhanced of which beyond those parameters, the strength reduced. Fig. 4e, which reflected interactions between particulate dosage and temperature and Fig. 4f which also depict interaction between pressure and temperature follow the same pattern. As in the case of Fig. 4e, increment in particulate proportion up to $4 \mathrm{wt}$. \% resulted in enhanced flexural strength nevertheless, the strength decreased with temperature rise. In Fig. 4f, rising pressure between 1 and $2 \mathrm{MPa}$ amounted to strength enhancement, whilst strength reduced with temperature beyond $2 \mathrm{MPa}$. In all interactions, it is deduced that flexural strength response of the eco-composite is dependent on the interactive pattern between the factors.

\subsection{D Process Mapping}

Contour/process mapping is a two-dimensional view which entail connection of points that produce same response value, through contour lines [32]. It reflects relationship between two continuous factors and the response. A feature of contour mapping is the revelation of regions in which varying values of the response can be attained at varying values of the parameters. One of the regions is the optimum zone; region in which optimal value can be/are obtained. Equally, varying values of the interactions between the parameters in achieving optimum response are highlighted from the map. In Fig. 5a, "A" depicts optimum region presenting range value of $>50 \mathrm{MPa}$; attainable at fiber loading of 8.3-13.5 wt. \% and particle dosage of 3.1-5.2 wt. \%. Region marked "B" in Fig. 5b illustrate optimal zone for flexural strength of $>50 \mathrm{MPa}$ at fiber loading of 8.213.5 wt. $\%$ and pressure of 1.7 to $2.6 \mathrm{MPa}$. The process map of the interaction between fiber dosage and temperature on flexural strength response is presented in Fig. 5c. Portion marked " $\mathrm{C}$ " is the optimum zone in which flexural strength of $>55 \mathrm{MPa}$ is attainable. In achieving the optimum range of strength within this region, fiber loading of 8.2-13.5 wt. \% and temperature range of $160-165{ }^{\circ} \mathrm{C}$ suffice. Similarly, in Fig. 5d, optimum zone " $\mathrm{D}$ " covers strength range of $>52 \mathrm{MPa}$, attainable at particle loading of 3.9-4.5 wt. \% and pressure of 2.2-2.35 MPa. Portion "E" in Fig. 5e, reveal optimum zone for flexural strength value of $>56 \mathrm{MPa}$ realizable at particle dosage of 3.5-4.8 wt. \% and 160$163.5{ }^{\circ} \mathrm{C}$. Fig. $5 \mathrm{f}$ shows the process map of interaction $\mathrm{C} \times \mathrm{D}$ (pressure $\mathrm{x}$ temperature) and as observed, optimal zone is identified as "F". Flexural strength $>55 \mathrm{MPa}$ is achievable with process parameters ranging from 1.752.35MPa for pressure and $160-166^{\circ} \mathrm{C}$ for pressure. 


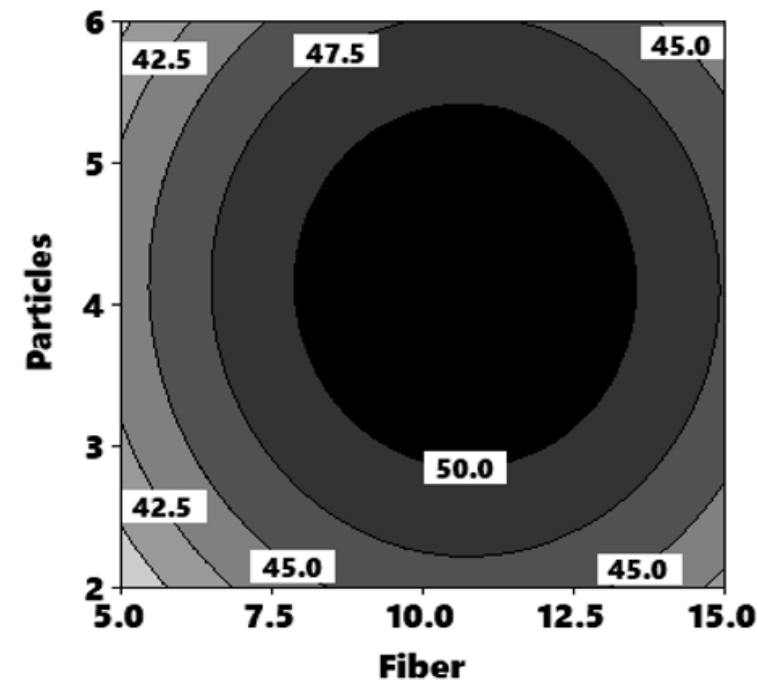

(a)

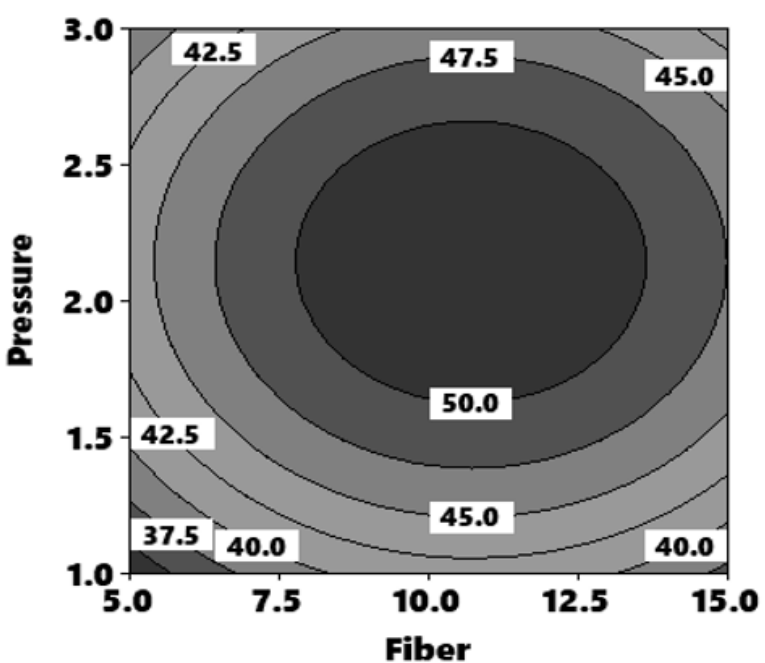

(b)

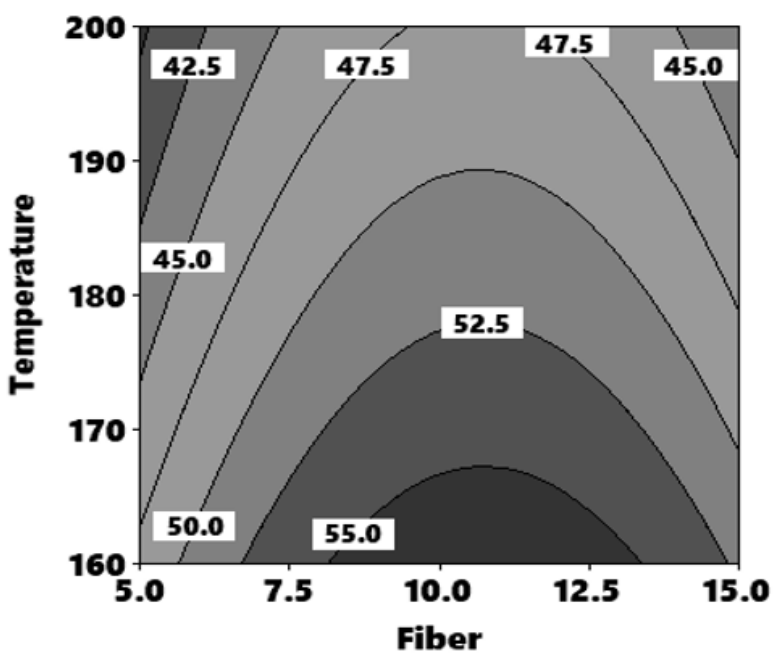

(c)

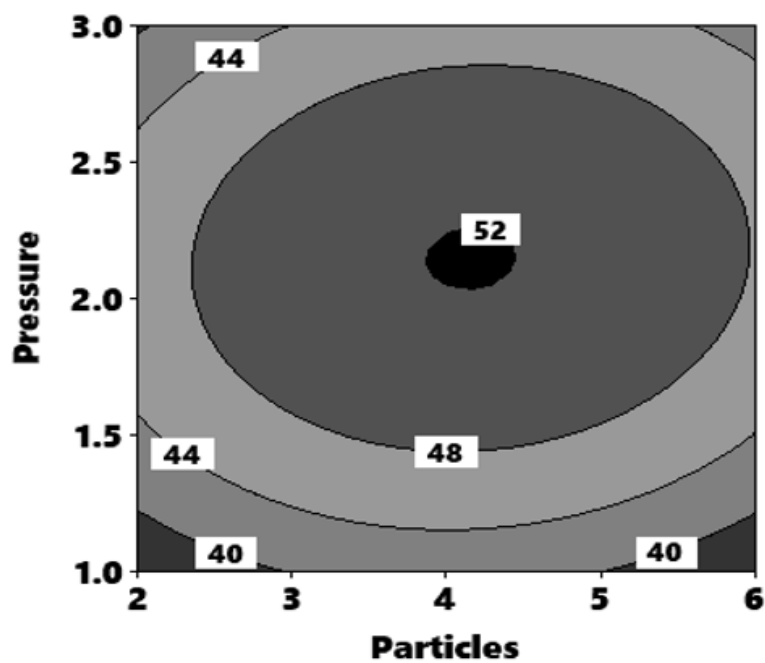

(d)

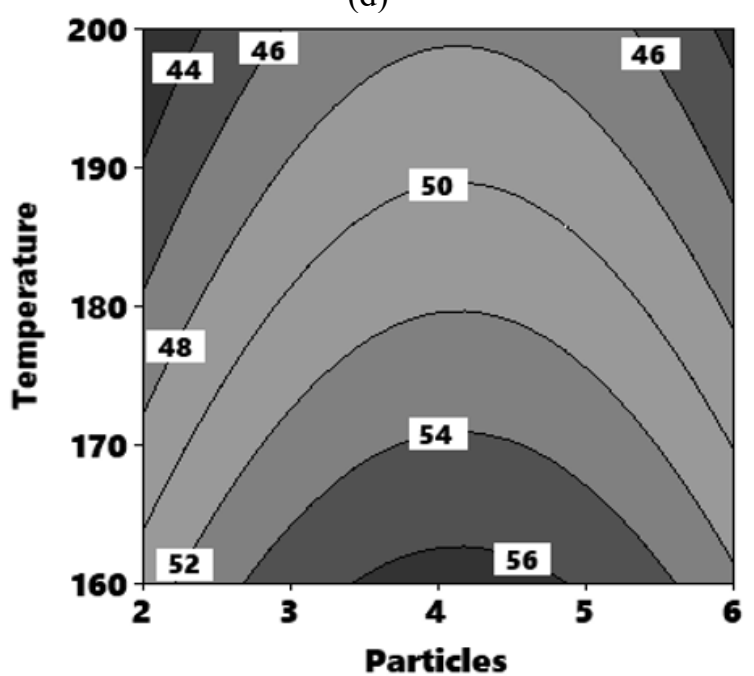

(e)

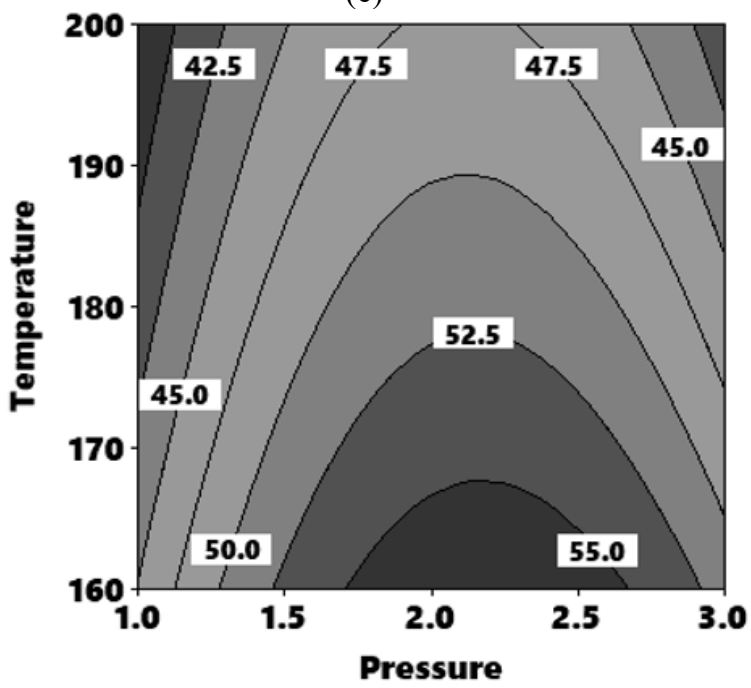

(f)

Fig. 5. Process map highlighting regions of variation in the response (flexural strength) obtained by combined interactions: (a) fiber vs particulate (b) fiber vs pressure (c) fiber vs temperature (d) particulate vs pressure (e) particulate vs temperature (f) pressure vs temperature 


\subsection{Optimization and validation of experimental factors and flexural strength response}

According to [33], response surface method (RSM) is a useful mathematical and statistical tool for multi variable optimization. With the use of Minitab 19, RSM was employed to optimize the factors. In the settings, the experimental factors were ranged between lower and upper limits and the flexural strength was maximized. Ten optimization solutions were obtained with varying desirability (Table). The one with the highest desirability of 0.9650 was chosen as depicted in Fig. 6. Optimum flexural strength of 57.15 MPa was predicted to be obtained when $10.76 \mathrm{wt}$. $\%$ fiber is combined with 4.18 wt. \% particulate at operating conditions of 2.19 $\mathrm{MPa}$ and $160{ }^{\circ} \mathrm{C}$ for pressure and temperature respectively. Flexural strength of the reference material is $42.6 \mathrm{MPa}$, therefore, optimal flexural strength showed $34.2 \%$ enhancement in strength relative to the reference $\operatorname{mix}(80-\mathrm{vPET} / 20-\mathrm{rPET})$.

Table 6. Predicted flexural strength of eco-composite at different optimization goals

\begin{tabular}{|l|l|l|l|l|l|l|}
\hline Solution & $\begin{array}{c}\text { Fiber } \\
\text { (wt. \%) }\end{array}$ & $\begin{array}{l}\text { Particles } \\
\text { (wt. \%) }\end{array}$ & $\begin{array}{c}\text { Pressure } \\
\text { (MPa) }\end{array}$ & $\begin{array}{l}\text { Temperature } \\
(\mathbf{C} \text { ) }\end{array}$ & $\begin{array}{l}\text { Flexural } \\
\text { strength } \\
\text { Fit }\end{array}$ & $\begin{array}{c}\text { Composite } \\
\text { Desirability }\end{array}$ \\
\hline 1 & 10.76 & 4.18 & 2.19 & 160.00 & 57.15 & 0.96 \\
\hline 2 & 10.57 & 4.46 & 2.46 & 165.72 & 54.97 & 0.90 \\
\hline 3 & 9.81 & 4.12 & 2.38 & 171.85 & 53.55 & 0.86 \\
\hline 4 & 10.70 & 5.76 & 1.99 & 160.00 & 53.51 & 0.86 \\
\hline 5 & 14.05 & 5.70 & 2.13 & 160.00 & 51.27 & 0.80 \\
\hline 6 & 14.12 & 2.37 & 2.07 & 160.00 & 50.23 & 0.77 \\
\hline 7 & 12.67 & 2.82 & 2.46 & 171.55 & 50.19 & 0.77 \\
\hline 8 & 8.24 & 2.88 & 2.53 & 168.45 & 50.09 & 0.77 \\
\hline 9 & 14.27 & 2.27 & 2.02 & 160.00 & 49.39 & 0.75 \\
\hline 10 & 6.44 & 5.67 & 2.02 & 160.00 & 49.22 & 0.74 \\
\hline
\end{tabular}

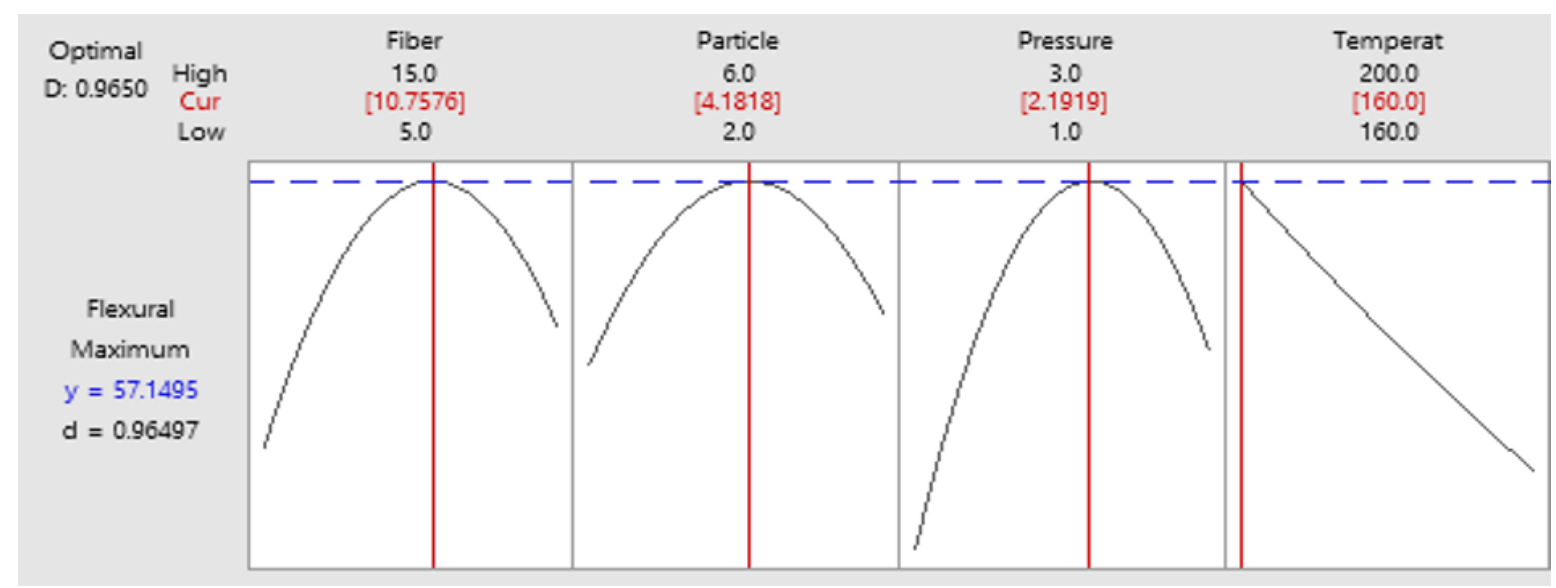

Fig. 6. Optimization plot for flexural strength.

In validating the result, five laboratory experiments were conducted using the optimum parameters. Mean result of $59.21 \mathrm{MPa}$ was attained for the experimental result and when compared with the predicted of 57.16 $\mathrm{MPa}$, there is an error of $3.6 \%$ and an enhancement of $39 \%$ enhancement over reference mix $(80$-vPET/20rPET). Since the error is insignificant $(<0.05)$, the model is validated. When compared with the flexural strength obtained for the optimum mix, experimental result of the optimum mix yielded improvement in flexural strength to the tune of $39 \%$.

\subsection{Morphological features}

As observed in the morphology of the fractured surface of the $80 / 20$-vPET/rPET composite, there exist a brittle failure (Fig 7a). This is attributed to none existence of reinforcing additives. Fig. $7 \mathrm{~b}$ presents the elemental composition of the unreinforced sample containing majorly carbon and oxygen elements typical of pure polymeric material. Fig 7c indicates the fractured morphology of composite sample produced at optimum condition.

There is dispersion of snail shell particulates and kenaf fiber within the structure. The image shows fiber presence which is interlocked with the polymer matrix hence finding it hard to pull out during fracture indicative of enhanced flexural strength. Equally, there is uniform dispersion of particles within the structure which increased interaction at the interface of particles and matrix. Additionally, the additives have good interaction with one another and with the matrix provoking even stress distribution within the matrix. 
This resulted in better strength performance when compared with the unreinforced one. Fig. 7d highlights the elemental composition of the optimized composite containing carbon, oxygen majorly. Presence of magnesium, calcium, aluminium and iron is on account of presence of reinforcing additives of kenaf fiber and snail shell particulate. The presence of these elements boasted the strength, yielding enhanced flexural performance as compared with the plain PET matrix.

\section{Conclusion}

The effects of the interaction of compression moulding parameters; fiber dosage, particulate dosage, molding pressure and temperature on flexural strength response were analysed, the following conclusions are made;

i. results of the ANOVA depict that the interactions of the parameters significantly affect the response. Moulding pressure was adjudged to have the highest contribution on the response followed by fiber dosage, particulate dosage and temperature in that order.

ii. quadratic model for the flexural strength of the developed composite was validated to be significant.

iii. analysis of the response surface method (RSM) revealed the response to be dependent on the manner of interactions which exist between the process variables. The process map showed different regions of strength attainment at varying combinations of parameters.

iv. Optimum flexural strength of the developed composite was realized at values of 10.76 wt. \%, 4.18 wt. \%, $2.19 \mathrm{MPa}$, and $160{ }^{\circ} \mathrm{C}$ for fiber proportion, particulate proportion, moulding pressure and temperature respectively which was an improvement of $34.2 \%$ improvement over the reference 80 -vPET/20rPET matrix.

v. Validation of the model was conducted using the values conditions stipulated in (iv) and flexural strength which showed +0.036 deviation was obtained and since the error is insignificant, the model was considered statistically fit.

Therefore, infusion of the agro additive to 80 -vPET/20rPET produce eco-composite of better flexural performance for food packaging application.
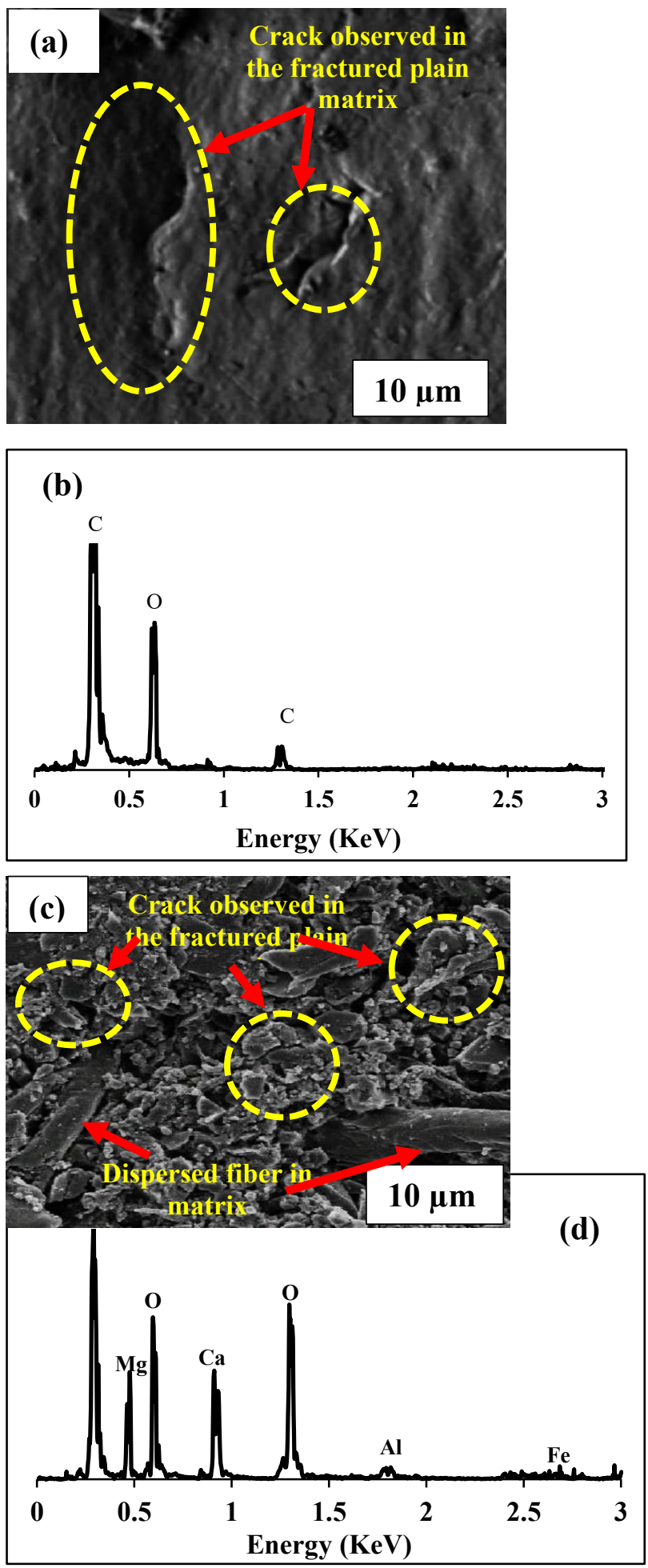

Fig. 7. Morphology and EDAX of (a, b) pure PET and (c, d) optimized PET composite

\section{References}

1. L. K. Ncube, A. C. Ude, E. N. Ogunmuyiwa, R. Zulkifli, Recycling, 6, 1 (2021

2. O. Kehinde, O. J. Ramonu, K. O. Babaremu, L. D. Justin, Heliyon, 6, 05131 (2020)

3. S. Karthikeyan, P. Arun, and M. P. Thiyaneswaran, AIP Conference Proceedings, 2235, 020020 (2020) 
4. P. Dwivedi, P. K. Mishra, M. K. Mondal, N. Srivastava, Heliyon, 5, e02198, (2019)

5. K. Maduna and V. Tomasic, Phys. Sci. Rev., 2, 12, 20160122, (2017), https://doi: 10.1515/psr-20160122.

6. F. Pereza, Int. J. Environ. Res. Public Health, 15, (2018)

7. M. E. Grigore, Recycling, 2, 1 (2017)

8. I. Kazulyte, J. Kruopiene, Environ. Res. Eng. Manag., 74, 19 (2018)

9. F. A. Chacon, M. T. Brouwer, E. U. Thoden van Velzen, Packag. Technol. Sci., 2020, 1, (2020)

10. A. Elamri, A. Lallam, O. Harzallah, L. Bencheikh, J. Mater. Sci., 42, (2007)

11. R. S. Chen, M. H. Ab Ghani, M. N. Salley, S. Ahmad, Mater. Sci. Appl., 5, 943 (2014)

12. A. A. Adediran, A. A. Akinwande, O. A. Balogun, O. S. Olasoju, O. S. Adesina, Sci. Rep., 11, 5465 , 1, (2021)

13. A. A. Adediran, O. A. Balogun, A. A. Akinwande, F. M. Mwema, O. S. Adesina, and A. Olayanju, Sci. world J., 2021, 8891563, 1 (2021)

14. M. S. Islam, Fracture and delamination in packaging materials: A study of experimental methods and simulation techniques, Blekinge Institute of Technology, Sweden, 2019.

15. G. C. Onuegbu and I. O. Igwe, Mater. Sci. Appl., 2, 811 (2011)

16. H. C. Obasi, J. Polym., 2015, 189289, 1(2015

17. I. O. Oladele, A. A. Adediran, A. D. Akinwekomi, M. H. Adegun, O. O. Olumakinde, O. O. Daramola, Sci. World. J. 2020, (2020)

18. J. Kim and D. Cho, 12, 2578, (2020), https://doi: $10.3390 /$ polym 12112578 .

19. H. Amur, N. A. Hassan, F. M. Fauzey, Adv. Mater. Res., 264-265, 743 (2011).

20. Y. Srithep, D. Pholharn, A. Dassakorn, and J. Morris, IOP Conf. Ser. Mater. Sci. Eng., 213, 012008, (2017)

21. L. Zhang, J. Zhai, Struct. Concr., 2020, 1, (2020)

22. O. S. Yordem, M. Mapila, Y. Z. Menceloglu, Mater. Des., 29, 34, (2008)

23. A. Buthiyappan, A. A. Abdul Raman, M. Davoody, W. M. A. Wan Daud, Chem. Eng. Commun., 204, 658-676, (2017)

24. S. O. Sada, Niger. J. Technol., 37, 2, 407 (2018)

25. I. A. Salem, A. R. Rozyant, Y. B. O. Betar, T. Adam, M. Mohammed, and A. M. Mohammed, IOP Conf. Ser. Physis, 908, 012001 (2017)

26. R. Udhayasankar, B. Karthikeyan, A. Balaji, J. Adhes. Sci. Technol., 1-21

27. M. Dash, A study on thermal characteristics of epoxy composites filled with natural fiber and particulate, National Institute of Technology, Rourkela, India, 2016.

28. A. D. 790-17, Standard test methods for flexural properties of unreinforced and reinforced plastics and electrical insulating materials, ASTM Int. West Conshohocken, PA, 2017.

29. K. Kumar, K. Prasad, P. Kundu, Express Polym. Lett., 3, 207 (2009).

30. X. Zhou, Q. Zhang, D. Chen, P. Lu, "Enhanced mechanical properties of graphene-based poly(vinyl alcohol) composites," Macromolecules, 43, 2357, (2010).

31. M. Khane, R. K. Gupta, B. Bhardwaj, Mater. Res. Express, 6, 126512, (2019).

32. B. Xu, J. Chen, M. Yao, Math. Probl. Eng., 2016, 3089690, 1, (2016)

33. T. F. Awolusi, L. O. Oke, O. O. Akinkurolere, D. P. Ubani, R. T. Bamisaye, O. G. Aluko, Silicon, 2020) 